Check for updates

Cite this: RSC Adv., 2017, 7, 30365

Received 1st May 2017

Accepted 7th June 2017

DOI: $10.1039 / \mathrm{c} 7 \mathrm{ra0} 4886 f$

rsc.li/rsc-advances

\section{Direct synthesis of carbon nanotubes on metallic foams as a cathode material with high mass load for lithium-air batteries}

\author{
Mihnea loan Ionescu (iD * \\ Carbon nanotubes (CNTs) were synthesized directly on metallic substrates by spray pyrolysis chemical \\ vapor deposition. Cathodes containing CNTs with mass loads up to $25.9 \mathrm{mg} \mathrm{cm}^{-2}$ were investigated for \\ $\mathrm{Li}$-air batteries and exhibited a maximum specific discharge capacity of $3348 \mathrm{~mA} \mathrm{~h} \mathrm{~g}^{-1}$ for a carbon \\ loading of $4.2 \mathrm{mg} \mathrm{cm}^{-2}$. These results demonstrate that carbon nanomaterials present electrocatalytic \\ activity for the cathode reaction and can be deposited and used directly as cathode materials for \\ developing energy storage devices with improved performances.
}

\section{Introduction}

Lithium-air batteries have a theoretical specific energy density comparable to the one of gasoline and have the potential to address the performance requirements for applications which require mobile energy storage devices such as electric vehicles and hybrid electric vehicles., ${ }^{\mathbf{1 , 2}}$ The development and the operation in plain air of this type of battery are more complex than initially prospected due to high over-potentials, unstable electrolytes, or poor cycling performances. In addition, obtaining cathodes with optimum mass load, surface area, and porosity, still represents a critical challenge. ${ }^{3}$

CNTs and their derivatives were used for cathode fabrication for lithium-air batteries due to their catalytic activity, good conductivity, high surface area, and chemical stability. Usually these materials are used in combination with binders and other additives. Recently, it was presented that cells fabricated using high loads of commercial carbon mixed binders have a specific capacity which decreases monotonically with increasing carbon loading. The highest area-specific capacity was found for a load of $15 \mathrm{mg} \mathrm{cm} \mathrm{cm}^{-2}$ which decreased for higher loadings due to a lower utilization of the active carbon. ${ }^{4}$ The utilization of high amounts of carbon active materials is rare and the current trend is to utilize only fraction of milligram of nanostructured carbon in metal-air batteries. Cathodes with a low mass loading of carbon have a small capacity per unit area which is not practical for the fabrication of energy storage devices with high power density. ${ }^{5}$ Moreover, these cells are mostly characterized in pure oxygen atmosphere and not in air which was the initial purpose of metal-air batteries for practical reasons. ${ }^{6}$ Regardless of the discharge environment or the mass load of carbon used for cathode fabrication, few research activities were previously

National Research Council Canada, 800 Collip Circle, London, Ontario, N6G 4X8, Canada. E-mail: mihnea.ionescu@nrc-cnrc.gc.ca; Tel: +1 5194307124 focused on preparing cathodes by direct synthesis of materials on the substrate without using additional materials. Schroeder et al., deposited CNTs directly on metallic foams covered with catalyst particles obtained by an atomic layer deposition process. ${ }^{7}$ Other research groups obtained binder-free electrodes for lithium-oxygen batteries containing pristine or nitrogendoped CNTs grown by using the floating catalyst chemical vapor deposition method..$^{89}$ The CNT load obtained on metallic foams by using these methods was not disclosed ${ }^{9}$ or was no more than $2 \mathrm{mg} \mathrm{cm}^{-2}$.7,8 To our best knowledge, no studies were conducted to grow carbon nanomaterials with mass loads of more than $2 \mathrm{mg} \mathrm{cm}^{-2}$, on conductive substrates, and used them directly as cathodes for energy storage applications. The main difficulty in increasing the mass load of CNTs on metallic substrates is to find ways to keep the catalyst metal active by avoiding its diffusion into the metallic substrate prior to CNT growth. Initializing the CNT synthesis before the catalyst arrives in the substrate proximity can be a solution to this challenge and can be realized by the spray pyrolysis CVD technique. By using this technique, during the growth process, a solution containing both the carbon source and the catalyst is sprayed inside the deposition chamber where the substrate is located.

This work was part of a large project carried out at NRC Canada, aiming at gaining a deeper fundamental understanding as well as developing technical solutions for a realistic large-scale Li-air battery. In this study, we deposited CNTs with

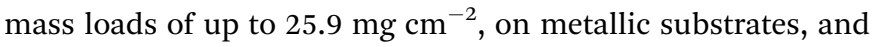
employed them as cathodes to study the effect of mass load on the discharge of lithium-air batteries. It was found that cathodes with a mass load of CNTs of $4.2 \mathrm{mg} \mathrm{cm} \mathrm{cm}^{-2}$ produced a maximum specific capacity. This finding is opening a rational direction in direct deposition of carbon nanostructured materials and their usage as electrodes in energy storage applications. 


\section{Experimental}

\subsection{Materials synthesis}

Nickel foam was cut into pieces of $20 \mathrm{~mm} \times 40 \mathrm{~mm}$ which were used as substrates for CNT synthesis. CNTs used in this work were synthetized by the spray pyrolysis chemical vapor deposition method detailed in our previous studies. ${ }^{\mathbf{1 0 , 1 1}}$ The deposition process consists in spraying an active solution into a quartz reactor, where substrates are located, when the temperature reached $750{ }^{\circ} \mathrm{C}$. The active solution was prepared by dissolving ferrocene $\left(\mathrm{Fe}\left(\mathrm{C}_{5} \mathrm{H}_{5}\right)_{2}\right)$ into xylene $\left(\mathrm{C}_{6} \mathrm{H}_{4}\left(\mathrm{CH}_{3}\right)_{2}\right)$ for a mass concentration of $0.025 \mathrm{~g} \mathrm{ml}^{-1}$. Ferrocene was used to produce metallic iron particles and to act as catalyst during the synthesis process. In the spraying process, argon was used as the carrier gas at a flow rate of $300 \mathrm{sccm}$. The solution was injected with

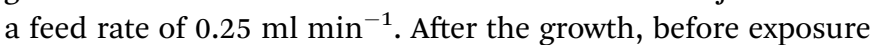
to air, the reactor was allowed to cool down under argon flow. The deposition process can be scaled-up by using deposition chambers which can accommodate bigger substrates. To demonstrate this concept and by using a deposition system build by one of our industrial partners (ECVD600 by Plasmionique Inc.), CNTs were also grown on substrates with a bigger surface area $(75 \mathrm{~mm} \times 100 \mathrm{~mm})$.

\subsection{Physical characterizations}

Structure and crystallinity of nanotubes were investigated by scanning electron microscopy (SEM - Hitachi S-4800), transmission electron microscopy (TEM - Hitachi H-7000), Raman spectroscopy (Raman - Renishaw 785 nm laser excitation), and by X-ray photoelectron spectroscopy (XPS - Kratos AXIS Ultra with $\mathrm{Al} \mathrm{K} \alpha$ as the X-ray source). Samples for SEM characterizations were obtained by cutting the foam after nanomaterial deposition in disks with a diameter of approx. $5 \mathrm{~mm}$. For the preparation of TEM samples, the foam containing the deposited nanomaterial was sonicated in ethanol for 10 minutes and few droplets of the resulted suspension were dried on a copper micro-grid. The mass load of CNTs was determined by subtracting the weight of the Ni foam from the overall weight of the foam containing the deposited nanomaterial. All masses were obtained using a precision balance with a resolution of $2 \times$ $10^{-5} \mathrm{~g}$ (AP250D, Ohaus).

\subsection{Electrochemical measurements}

Cathodes were prepared for usage in lithium-air batteries, without using any additional binder or catalyst material, by cutting the nickel foams coated with CNTs in discs with $13 \mathrm{~mm}$ diameter. For electrochemical tests, batteries were assembled in
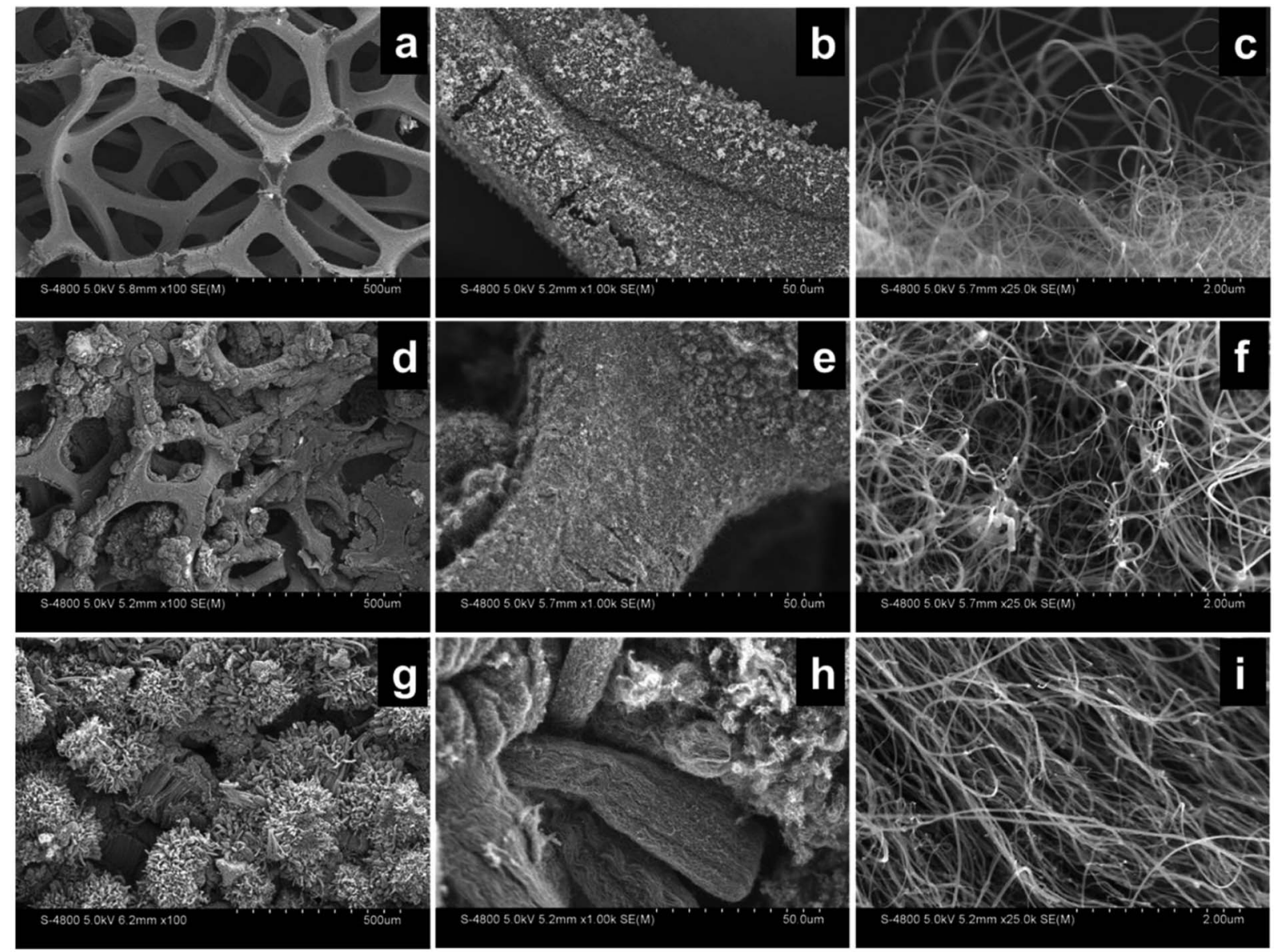

Fig. 1 SEM images at different magnifications of CNTs deposited on Ni foams with mass loads of (a-c) $4.2 \mathrm{mg} \mathrm{cm}^{-2}(\mathrm{~d}-\mathrm{f}) 9.8 \mathrm{mg} \mathrm{cm}{ }^{-2}$, and $(\mathrm{g}-\mathrm{i})$ $25.9 \mathrm{mg} \mathrm{cm}^{-2}$. 
an argon filled glove box (MBraun, $\mathrm{O}_{2}<0.1 \mathrm{ppm}, \mathrm{H}_{2} \mathrm{O}<0.1$ ppm) using a modular battery assembly (El-Cell, ECC-Air). Lithium foil was used as the anode and was separated by the cathode by a using a glass fiber separator (EL-Cell, $0.65 \mathrm{~mm}$ thickness). The electrolyte was a $1 \mathrm{M}$ solution of lithium trifluoromethanesulfonate $\left(\mathrm{LiCF}_{3} \mathrm{SO}_{3} 99.9 \%\right.$, Sigma Aldrich) dissolved in tetraethylene glycol dimethyl ether (TEGDME 99\%, Sigma Aldrich). The electrochemical tests were performed using a potentiostat-galvanostat instrument (Solartron SI 1287, Solartron Analytical), in the voltage range of $2.0-4.5 \mathrm{~V}$, at a discharge current density of $0.1 \mathrm{~mA} \mathrm{~cm}^{-2}$, in dry air, at $20^{\circ} \mathrm{C}$.

\section{Results and discussion}

The mass load of CNTs on Ni foam substrates was controlled by changing the volume of active solution injected during the synthesis process. Five sets of experiments were conducted using $0.8,1.2,2.0,4.3$, and $10 \mathrm{ml}$ for obtaining metallic foams with CNT mass loads of 2.7, 4.2, 5.7, 9.8, and $25.9 \mathrm{mg} \mathrm{cm}^{-2}$.

SEM images for foams with a carbon load of 4.2, 9.8, and $25.9 \mathrm{mg} \mathrm{cm}^{-2}$, reveal an overall carpet-like deposit containing highly dense CNT arrays, without evident catalyst impurities, which fully covers the metallic foams (Fig. 1).

For a mass load of $4.2 \mathrm{mg} \mathrm{cm}^{-2}$, the nanotubes are not long enough (12 $\mu \mathrm{m}$ average length) to hide the open structure of the metallic foam (Fig. 1a-c). For a mass load of $9.8 \mathrm{mg} \mathrm{cm}^{-2}$ the nanotubes have an average length of $41 \mu \mathrm{m}$ and the foam structure is still visible, although the open cells have been reduced considerably (Fig. 1d-f). CNTs with a mass load of
$25.9 \mathrm{mg} \mathrm{cm}^{-2}$ grown in bundles of aligned tubes with an average length of $182 \mu \mathrm{m}$ long which are long enough to completely fill the void space in the open cell structure of the metallic foam (Fig. 1g-i). The structure of CNTs is similar for all samples and TEM, XPS, and Raman characterisations are presented only for samples containing CNTs with a mass load of $4.2 \mathrm{mg} \mathrm{cm} \mathrm{cm}^{-2}$ (Fig. 2). CNTs have a diameter distribution between 20 and $100 \mathrm{~nm}$ and present a neglected amount of amorphous carbon or catalyst particles encapsulated in the inner core or attached on the nanotube surface as seen in the TEM image (Fig. 2a).

XPS spectrum is shown in Fig. $2 \mathrm{~b}$ and indicates a strong peak at $284 \mathrm{eV}$ attributed to C1s. Two other peaks visible at $532 \mathrm{eV}$ and $710 \mathrm{eV}$ are attributed to $\mathrm{O} 1 \mathrm{~s}$ and Fe2p. The atomic concentration of oxygen and iron as detected by XPS measurements was 0.99 at $\%$ and 0.11 at\%, showing a low degree of surface oxidation for synthetized CNTs and confirming the TEM observations which indicate the deposition of CNTs with a low amount of catalyst impurities. Fig. 2c shows the Raman spectrum of CNTs (Fig. 2c) with a strong band around $1603 \mathrm{~cm}^{-1}$, which is referred to as the G-band. The G-band corresponds to the optical phonon modes of $E_{2 \mathrm{~g}}$ symmetry in graphite and indicates the formation of well graphitized carbon nanotubes. The D-band at $1376 \mathrm{~cm}^{-1}$ originates from defects that occur in the curved graphene layers and at the end of the tubes. The defects in the CNT structure promote the adsorption of oxygen and of reactive intermediates which enhanced the oxygen reduction reaction. ${ }^{12}$ There were no evident differences between Raman spectra obtained for samples with different mass loads.
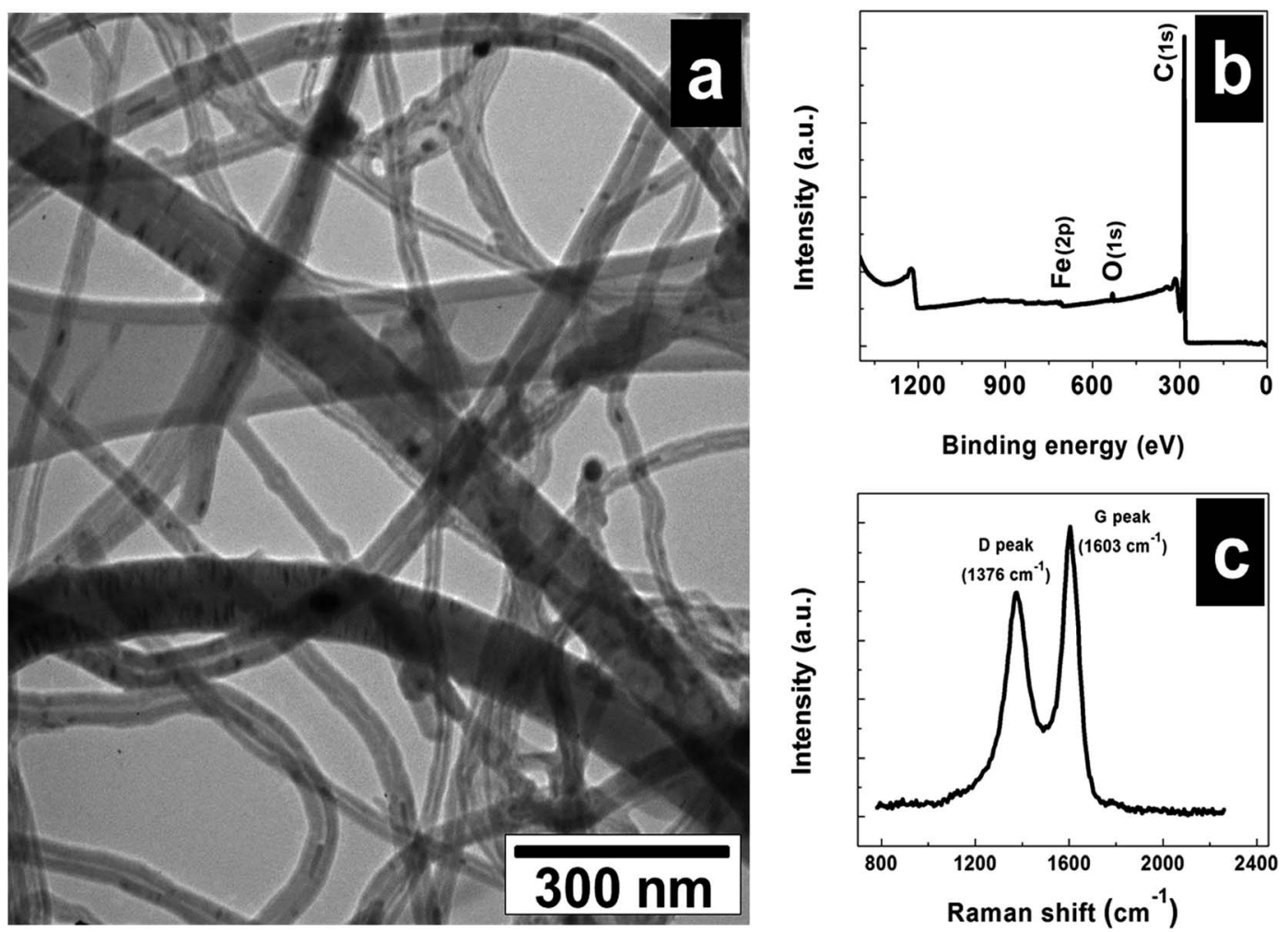

Fig. 2 TEM, XPS, and Raman spectrum for CNTs with a mass load of $4.2 \mathrm{mg} \mathrm{cm}^{-2}$. 

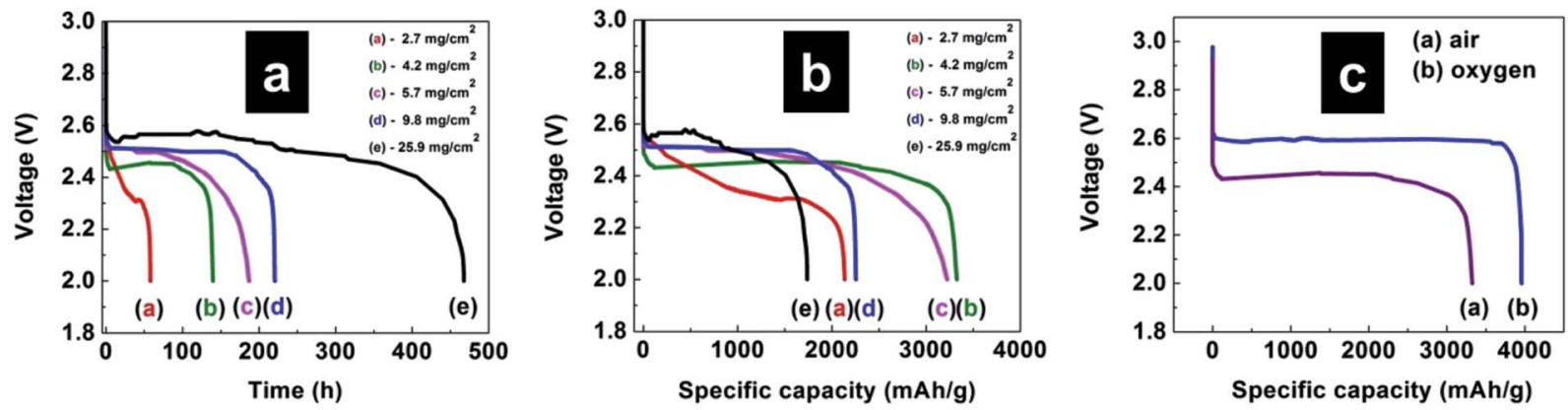

Fig. 3 (a and b) discharge curves for cathodes with different mass loads of CNTs and (c) discharge curves for cathodes with a mass load of 4.2 mg $\mathrm{cm}^{-2}$ conducted in dry air and in oxygen atmosphere. The discharge current density was $0.1 \mathrm{~mA} \mathrm{~cm}{ }^{-2}$ for all curves.

The discharge curves for cathodes with different mass loads of CNTs are presented in Fig. 3. With increasing the mass load from $2.7 \mathrm{mg} \mathrm{cm} \mathrm{cm}^{-2}$ to $25.9 \mathrm{mg} \mathrm{cm}^{-2}$, the discharge time increased from $58.5 \mathrm{~h}$ to $467 \mathrm{~h}$ and the voltage plateau also increased from $2.31 \mathrm{~V}$ to a maximum of $2.55 \mathrm{~V}$ (Fig. 3a).

Initial discharge capacity curves obtained for cathodes with different mass loads are presented in Fig. 3b. Cathodes with a mass load of $4.2 \mathrm{mg} \mathrm{cm}^{-2}$ produced the optimum catalytic activity and a maximum specific capacity of $3321 \mathrm{~mA} \mathrm{~h} \mathrm{~g}^{-1}$. When the carbon loading is less than $4.2 \mathrm{mg} \mathrm{cm}^{-2}$, the specific capacity of the cell decreases because less active material is used in the discharge process. When the carbon loading exceeds $4.2 \mathrm{mg} \mathrm{cm}^{-2}$, the specific capacity also decreases because longer CNTs lead to a lower utilization of carbon sites situated close to the metallic substrate. All electrochemical characterizations were conducted in dry air. However, most of the research work conducted for developing metal-air energy storage devices, presented results obtained using oxygen as working environment. While such approach is might not be practical, it gives the possibility to repeat and compare results obtained by different research groups. For this reason, in comparison with the discharge experiment conducted in dry air for cathodes with optimum mass load of $4.2 \mathrm{mg} \mathrm{cm}^{-2}$ CNTs, the discharge curve was also obtained in oxygen atmosphere by using cathodes with identical mass loads. As seen in Fig. 3c, the voltage plateau increased from $2.45 \mathrm{~V}$ to a $2.59 \mathrm{~V}$ and the specific capacity also increased from $3321 \mathrm{~mA} \mathrm{~h} \mathrm{~g}^{-1}$ to $3958 \mathrm{~mA} \mathrm{~h} \mathrm{~g}^{-1}$. Previous results reported on the subject of fabricating the cathode electrode using CNTs with the addition of binders delivered initial discharge capacities, in oxygen, between $590 \mathrm{~mA} \mathrm{~h} \mathrm{~g}^{-1}$ and 3483 $\mathrm{mA} \mathrm{h}{ }^{-1} \cdot{ }^{13,14}$ These values are lower than the value presented in this study even though the amount of CNTs $\left(0.5 \mathrm{mg} \mathrm{cm}^{-2}\right)$ and the discharge current density $\left(0.05 \mathrm{~mA} \mathrm{~cm}^{-2}\right)$ were lower. Better specific capacity value of $5142 \mathrm{~mA} \mathrm{~h} \mathrm{~g}^{-1}$ have been obtained for electrodes fabricated using CNTs without additives, at a current density of $0.1 \mathrm{~mA} \mathrm{~cm}^{-2} .8$ The CNT mass load of $1 \mathrm{mg} \mathrm{cm}^{-2}$ used was also lower than mass load values presented in this study. In addition to the first discharge capacities reported herein, more experimental results such as characterizations of discharged products and capacity retention on cycling are necessary for a better understanding of discharge mechanism and for optimizing the performance of cathodes. Furthermore, variations in the carbon nanostructure, in the material density, or in the doping percentage could produce cathodes which better utilize the active sites of the material even at high carbon loads.

\section{Conclusions}

CNTs with mass loads of up to $25.9 \mathrm{mg} \mathrm{cm} \mathrm{cm}^{-2}$ were directly deposited on metallic foam substrates and investigated as cathode materials for Li-air batteries. Cathodes operated in a dry air environment and those with a mass load of $4.2 \mathrm{mg}$ $\mathrm{cm}^{-2}$ demonstrated the highest specific capacity where the optimal balance between the carbon utilization and the mass loading was obtained. This finding gives a rational direction to explore other carbon materials which can be deposited with high loads directly on metallic substrates for application in lithium-air batteries.

\section{Acknowledgements}

This research was supported by the ecoENERGY Innovation Initiative (ecoEII) Program of Natural Resources Canada (NRCan) through project ETRI-006, as well as the Vehicle Propulsion Technologies program of NRC Canada.

\section{References}

1 K. M. Abraham and Z. Jiang, A Polymer Electrolyte-Based Rechargeable Lithium/Oxygen Battery, J. Electrochem. Soc., 1996, 143, 1-5.

2 M. A. Hannan, M. M. Hoque, A. Mohamed and A. Ayob, Review of energy storage systems for electric vehicle applications: issues and challenges, Renewable Sustainable Energy Rev., 2017, 69, 771-789.

3 A. Kraytsberg and Y. Ein-Eli, Review on Li-air batteriesopportunities, limitations and perspective, J. Power Sources, 2011, 196, 886-893.

4 J. Xiao, D. Wang, W. Xu, D. Wang, R. E. Williford, J. Liu and J.-G. Zhang, Optimization of Air Electrode for Li/Air Batteries, J. Electrochem. Soc., 2010, 157, A487-A492.

5 J. Christensen, P. Albertus, R. S. Sanchez-Carrera, T. Lohmann, B. Kozinsky, R. Liedtke, J. Ahmed and 
A. Kojic, A Critical Review of Li/Air Batteries, J. Electrochem. Soc., 2011, 159, R1-R30.

6 J. Wang, Y. Li and X. Sun, Challenges and opportunities of nanostructured materials for aprotic rechargeable lithiumair batteries, Nano Energy, 2013, 2, 443-467.

7 M. A. Schroeder, M. Noked, S. B. Lee and G. W. Rubloff, Binder-Free, Vertically Aligned Carbon Nanotubes on Nickel Foam as a Freestanding 3D Li-O $\mathrm{O}_{2}$ Battery Cathode, ECS Meeting Abstracts MA2014-02, 2014, 498.

8 R. Mi, S. Li, X. Liu, L. Liu, Y. Li, J. Mei, Y. Chen, H. Liu, H. Wang, H. Yan and W.-M. Lau, Electrochemical performance of binder-free carbon nanotubes with different nitrogen amounts grown on the nickel foam as cathodes in $\mathrm{Li}-\mathrm{O}_{2}$ batteries, J. Mater. Chem. A, 2014, 2, 18746-18753.

9 X. Lin, X. Lu, T. Huang, Z. Liu and A. Yu, Binder-free nitrogen-doped carbon nanotubes electrodes for lithiumoxygen batteries, J. Power Sources, 2013, 242, 855-859.

10 M. I. Ionescu, Y. Zhang, R. Li, X. Sun, H. Abou-Rachid and L.-S. Lussier, Hydrogen-free spray pyrolysis chemical vapor deposition method for the carbon nanotube growth: parametric studies, Appl. Surf. Sci., 2011, 257, 6843-6849.

11 M. I. Ionescu, Y. Zhang, R. Li, H. Abou-Rachid and X. Sun, Nitrogen-doping effects on the growth, structure and electrical performance of carbon nanotubes obtained by spray pyrolysis method, Appl. Surf. Sci., 2012, 258, 45634568.

12 C. V. Rao, C. R. Cabrera and Y. Ishikawa, In Search of the Active Site in Nitrogen-Doped Carbon Nanotube Electrodes for the Oxygen Reduction Reaction, J. Phys. Chem. Lett., 2010, 1, 2622-2627.

13 Y. Li, J. Wang, X. Li, J. Liu, D. Geng, J. Yang, R. Li and X. Sun, Nitrogen-doped carbon nanotubes as cathode for lithiumair batteries, Electrochem. Commun., 2011, 13, 668-672.

14 R. Mi, H. Liu, H. Wang, K.-W. Wong, J. Mei, Y. Chen, W.-M. Lau and H. Yan, Effects of nitrogen-doped carbon nanotubes on the discharge performance of Li-air batteries, Carbon, 2014, 67, 744-752. 